\title{
The Single Client Resonance Model: Beyond Rigor and Relevance
}

\author{
T. Grandon Gill \\ University of South Florida, Tampa, Florida, USA
}

ggill@coba.usf.edu

\begin{abstract}
Once a message meets the criteria of rigor and relevance, it may still fail to inform a client if it lacks resonance: the ability to impact client mental models. To achieve resonance with an individual client involves issues beyond the nature of the message itself. Filters that can interfere with resonance include informational, cognitive, risk/time preference, motivational, and visceral (e.g., emotions, moods). These are found to operate differently at different levels of structural complexity. As a consequence, the nature of the challenges faced when informing a single client can vary considerably depending upon the client's existing base of knowledge, psychological state, and the nature of the informing to be accomplished. The types of informing challenges likely to be encountered as a consequence of these filters - and how these challenges may be addressed - are examined with the goal of identifying what needs to be understood about the client in order to inform effectively.
\end{abstract}

Keywords: Resonance; task complexity; task structure; structural complexity; informing filters; rigor, relevance; cognitive science; informing science.

\section{Introduction}

To understand what is information for a client, one must understand the client's task. To maximize the form, format, and schedule, one must understand not only the task, but also the client's psychology. (Cohen, 1999)

When Eli Cohen proposed the informing sciences as a new transdiscipline, he made it clear that maximizing the "effectiveness" of the information provided to the client was integral to the definition of the field. Such effectiveness, however, cannot be achieved solely though achieving quality on the part of the sender and usefulness with respect to the task being performed by the client. As stated in the opening quote, if informing is to have a meaningful impact on the client, an understanding of the psychological characteristics of that client will be critical.

A recent article relating to the future of informing sciences discipline (T. G. Gill \& Bhattacherjee,

Material published as part of this publication, either on-line or in print, is copyrighted by the Informing Science Institute. Permission to make digital or paper copy of part or all of these works for personal or classroom use is granted without fee provided that the copies are not made or distributed for profit or commercial advantage AND that copies 1) bear this notice in full and 2) give the full citation on the first page. It is permissible to abstract these works so long as credit is given. To copy in all other cases or to republish or to post on a server or to redistribute to lists requires specific permission and payment of a fee. Contact Publisher@InformingScience.org to request redistribution permission.
2007) echoed this theme. The authors argued that the traditional dichotomy of rigor (research quality from a discipline's perspective) versus relevance (potential utility of the research to client activities) was misleading. A third characteristic, resonance-reflecting the ability of the research message to move through available channels to the client and, subsequently, to impact that client's mental models - is also a prerequisite of 
effective informing. If, for example, research results are presented in a format that makes them nearly incomprehensible to practitioner clients (e.g., emphasizing descriptions of research methodology and employing advanced statistical techniques for purposes of significance testing) and are disseminated through channels that do not reach these clients (e.g., academic journals), the quality of the research and its potential usefulness will not matter. The client will likely remain uniformed.

Achieving resonance is no easy task. To begin with, it often involves two distinct processes, that of sender-to-client informing and, subsequently, that of client-to-client informing (e.g., word-ofmouth). For example, research into the diffusion of innovations finds that while the sender-toclient process can be highly effective in informing "innovator" clients during the early stages of diffusion, later stages of diffusion nearly always depend upon client-to-client informing (Rogers, 2003). Thus, understanding both of these processes is likely to be a prerequisite for effective informing.

The present paper focuses exclusively on the sender-to-client resonance phenomenon and emphasizes client-side processes. We begin with a historical case study that illustrates how informing can fail despite both a rigorously tested message and an idea that was clearly useful. We then examine the existing research published in the informing science field, noting the relatively small emphasis that has been placed upon investigating sender-to-client resonance. A survey of the broad array of potentially relevant findings from a wide range of disciplines-including contributions from psychology, education, anthropology, the cognitive sciences, and management - then follows. From this, insights into what types of messages will and will not resonate with clients are distilled. Finally, these findings are synthesized into a general model of single client resonance. The hope is that this synthesis will benefit researchers interested in better understanding the full scope of the informing process and that such understanding will stimulate further research into the nature of resonance and how such resonance can be encouraged.

\section{A Case Study: Morison's Gunfire at Sea}

Within the innovation literature, a widely cited example that highlights the challenges of achieving acceptance of an idea is presented in Elting Morison's Man, Machines and Modern Times (1966). The case study, summarized below, describes the obstacles experienced in attempting to convince naval authorities of the validity of a new way to fire the guns installed on U.S. naval vessels.

By way of context, achieving accuracy when firing shipboard guns has always been more problematic than achieving comparable accuracy with land-based artillery. The main source of the difficulty is the rolling of the ship, which means that the angle of the gun's barrel is always changing. As a consequence, as late as at the turn of the $20^{\text {th }}$ century, individual gunners had to develop personalized approaches to compensating for the movement. Morison (1966, p. 21) describes the process as follows:

First of all, the rapidity of fire was controlled by the rolling period of the ship. Pointers [gunners] had to wait for the one moment in the roll when the sites were brought on the target. Notice also this: There is in every pointer what is called a "firing interval" - that is a time lag between his impulse to fire the gun and the translation of this impulse into the act of pressing the firing button. A pointer, because of this reaction time, could not wait to fire the gun until the exact moment when the roll of the ship brought the sights into the target; he had to will to fire a little before, while the sites were off the target. Since the firing interval was an individual matter, varying obviously from man to man, each pointer had to estimate from long practice his own interval, and compensate for it accordingly. 
Another factor impacting accuracy involved the gun sights. Although telescopic sights were sometimes provided to enlarge the target, they were attached to the gun barrel and "recoiling with the barrel, jammed back against the unwary pointer's eye" (Morrison, 1966, p. 21). Thus, while useful in estimating target range, they were virtually never used during the actual firing process.

In 1898, an English officer-Admiral Percy Scott - developed an alternative approach to firing guns that involved continuous aiming. This approach involved three relatively minor changes to the physical equipment - changing the gear ratio on the guns, mounting a simulated target on the mouth of the gun, and changing the telescopic mountings so they did not recoil into the pointer's eye upon firing - and a major change to firing procedures: having the pointer continuously adjust the gun elevation so that it was always on the target. The results of this innovation were astounding:

In 1899 five ships of the North Atlantic Squadron fired five minutes each at a lightship hulk at the conventional 1600 yards. After twenty-five minutes of banging away, two hits had been made on the sails of the elderly vessel. Six years later one naval gunner made fifteen hits in one minute at a target 77 by 25 feet at the same range - 1600 yards; half of them hit in a bull's-eye 50 inches square (Morison, 1966, p. 22).

In 1900, while serving in China, Scott met a junior U.S. naval officer, William S. Sims, who eagerly embraced the new approach and made the modifications necessary to institute the technique on his own ship. After a few months of practice, he demonstrated astounding improvements in accuracy, after which he began to communicate his findings with his U.S. Navy superiors in a series of 13 reports. Described by Morison (p. 22):

Over a period of two years, he reiterated three principal points: first, he continually cited records established by Scott's ships, the Scylla and the Terrible, and supported these with accumulating data from his own tests on an American ship; second, he described the mechanisms used and the training procedures instituted by Scott and himself to obtain these records; third, he explained that our own mechanisms were not generally adequate without modification to meet the demands of continuous-aim firing.

From an informing perspective, these messages clearly demonstrated two things. First, the quality of the information was rigorously supported by multiple sources of the evidence. Second, the usefulness of the approach to the client (i.e., the U.S. Navy) was shown through outcome-based measures. Thus, the conditions of both rigor and relevance were clearly met. What transpired thereafter, however, illustrates how quality and usefulness may not be sufficient to ensure that effective informing takes place.

Morison (1966) described the Navy's reaction as taking place in three stages. During the first stage, Sims's reports were simply ignored. Indeed, after being filed away they were largely consumed by cockroaches - the $19^{\text {th }}$ century analog to media failure. From an informing standpoint, this represents failure to attend to the channel. This failure of informing appears to have an underlying source that is mainly motivational in character: the individuals who received the correspondence had no particular interest in their contents.

After his initial efforts failed, Sims adopted a more strident tone in his reports and also began circulating them to other naval officers in the fleet. Described by Morison (p. 28-29):

Aware as a result that Sims's gunnery claims were being circulated and talked about, the men in Washington were then stirred to action. They responded, notably through the Chief of the Bureau of Naval Ordnance, who had general charge of the equipment used in gunnery practice, as follows: (1) our equipment was in general as good as the British; (2) since our equipment was as good, the trouble must be with the men, but gun pointers and 
the training of gun pointers were the responsibility of the officers on the ships; and most significant (3) continuous-aim firing was impossible.

The third of these was based on experiments, conducted in Washington Navy Yard, where it was found that five men could not operate the gears fast enough to achieve the rate of changes in the gun barrel angle that were required to support continuous aiming. In his rebuttal to the last point, Sims pointed out that the fixed platform test was invalid; instead, the rolling of the ship provided momentum to the gun barrel that actually made continuous aiming much easier.

From an informing standpoint, the three elements of the response from Washington clearly illustrate a practical challenge to achieving resonance: the existence of prior mental models. The client belief that U.S. equipment could not be inferior to that used by the British made accepting Sims's premise much more difficult. The belief that the accurate gunnery could only be achieved through training and that the task was a ship's responsibility - rather than that of the bureaucaused the client to question the relevance of the information. Finally, knowledge of the existing test caused the client to question the veracity of the information. Conceptually, then, prior mental models distorted the information during the communications process. As a consequence, the client's interpretation of the message did not match the sender's intent.

Returning to the narrative, Sims's increasingly agitated tone ultimately led to the third stage: "name-calling". Described by Morison (p. 31):

He was told in official endorsements on his reports that there were others quite as sincere and loyal as he and far less difficult; he was dismissed as a crackbrained egotist; he was called a deliberate falsifier of evidence.

In this stage, the principal obstacle to informing was less a matter of distortion resulting from prior mental models than of outright refusal to change existing models. There was no longer any desire to believe Sims; indeed the clients had an active interest in disbelieving him. Morison (1966, p. 36) further argues that a secondary but critical further source of resistance came from the implications that would necessarily result from the acceptance of the idea. Gunnery had always been perceived as an art rather than a science. As such, it has occupied a relatively low status position in the increasingly technological Navy. Sims's innovation would transform the nature of the task -increasing the status of gunnery with respect to other shipboard activities (such as ship handling) and prospects for promotion. In the context of an organization that had only recently made the transition from sail to steam and was still adjusting to its aftereffects, the motivation to accept the information that Sims was communicating was low indeed. This demonstrates that, in the informing context, failure to consider or accommodate the client's intrinsic motivation can lead to a complete breakdown of the informing process. When such motivational conflicts are present, message distortion is no longer the issue. The complete unwillingness of the client to modify existing mental models is the source of the problem. The described nature of the communication also indicates the important role that emotions can play in the informing context.

Ultimately, Sims broke the informing deadlock by writing directly to Theodore Roosevelt, then President of the United States. Roosevelt brought Sims back to the U.S. and assigned him to the post "inspector of Target Practice", where he continued for six years. During that period, his innovation diffused throughout the Navy and he was ultimately acclaimed as "the man who taught us how to shoot", eventually making Admiral and getting a warship named after him (USS William S Sims, DE/FF-1059). This would be an example of a case where intrinsic motivation failed using a particular channel. As a result, an alternative channel was needed and considerable extrinsic motivational force had to be applied.

In summarizing this case from an informing standpoint, we can see three key elements of what we'll refer to as resonance. Even after rigor and relevance has been established, the content needs 
to be internalized and made available for later recall, something that did not happen for the early letters owing to lack of motivation on the part of the client. The amount of distortion between the sender's intent and the client's interpretation needs to be minimized, a failure evident in the first response received by Sims; a consequence of initial differences between sender and client mental models. Finally, the client must be willing to restructure his or her mental models to incorporate the content, another motivational issue that is also subject to significant emotional forces. If any of these prerequisites of resonance are not met, the informing can fail.

\section{Resonance in the Informing Sciences Literature}

A principal objective of the current paper is to encourage research into the resonance phenomenon within the informing sciences. A useful starting point in reviewing resonance-related research, therefore, is to consider what findings already exist within the informing sciences literature. In this context, it makes sense to specifically limit our review to articles published within the Informing Sciences Institute family of publications, saving our broader review of the concept for the later sections in which the model is developed.

As noted in the introduction, the term resonance was introduced in an article that proposed a research agenda for the informing sciences (T. G. Gill \& Bhattacherjee, 2007). The authors suggested the term was needed to augment the concepts of rigor and relevance in order to describe "the ability of ... research to bridge the divide between sender and client" (T. G. Gill \& Bhattacherjee, 2007, p. 31). They further proposed that it consists of two parts: 1) the ability to resonate within a single client, and 2) the ability to promote subsequent client-to-client informing. In the context of promoting the informing sciences, the authors further proposed various recommendations relating to resonance, such as creating resonant examples of informing science applications and establishing a portfolio of publication types (to ensure resonance across different disciplines which may favor different presentations of scholarship, such as books vs. journal articles and case studies vs. quantitative research).

In a study of the Australian film industry (Alony, Whymark, \& Jones, 2007), numerous resonance-related phenomena were observed to facilitate the transfer of tacit information among participants. Among these were participant diversity, strength of ties, cohesion and trust. Several of these appear to relate to credibility, also an important issue raised in the case study. Gackowski (2006) points out the multidimensional nature of credibility, further arguing that it is a critical component of the information quality construct.

One research study that particularly relates to resonance issues examines how client biases act as filters on information received (Jamieson \& Hyland, 2006). As shown in Figure 1, four different filters are proposed:
1) information biases,
2) cognitive biases,
3) risk biases, and
4) uncertainty biases.

Information biases reflect mechanisms that modify incoming information to align it with existing client preferences, usually applied at an unconscious level. Cognitive biases are employed to simplify decision making so as to keep it within the limits of the client's bounded processing resources. Risk and uncertainty biases derive from client attitudes towards risk and uncertainty, respectively. Because these filters, particularly the first two, can serve to block information altogether, they can act as severe impediments to resonance. 


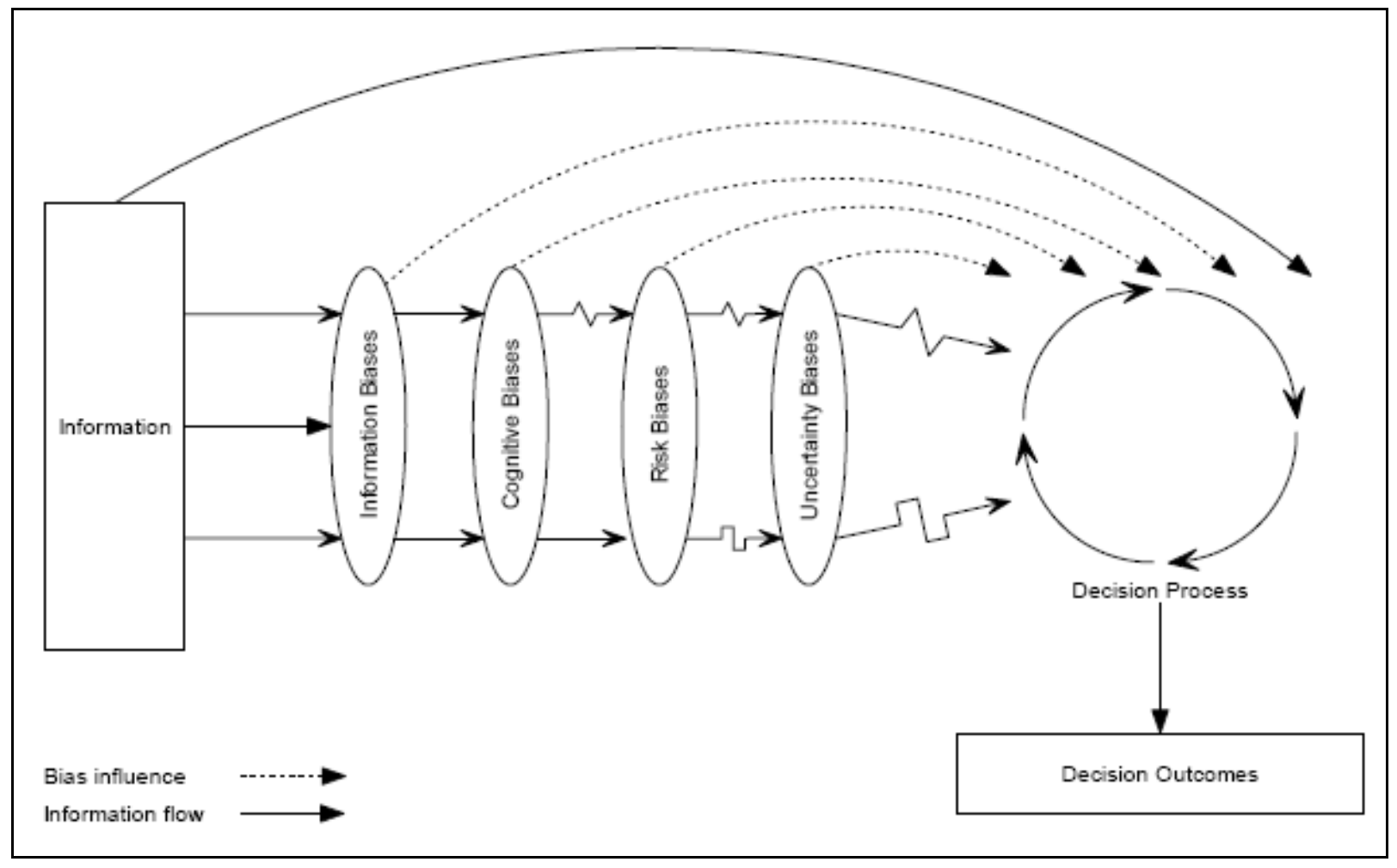

Figure 1: Client Information Filters (from Jamieson \& Hyland, 2006)

In a synthesis of the literature on task complexity (T. G. Gill \& Hicks, 2006), it is noted that several existing task complexity definitions relate task complexity to motivational characteristics and to the nature of the task performer's mental models (i.e., problem space). It therefore follows that a strong interaction between task complexity and resonance can be expected.

The specific impact of structural complexity on informing (T. G. Gill, 2008c) has been examined. The model of task structure that was proposed uses a problem space - consisting of a state space (schemata), operator space (operators and control knowledge), and a goal space (consisting of goals and a goal fitness operator) - and examines how the qualitative nature of task knowledge changes with accumulating expertise. Within each space, a top level (Level 4) consists entirely of general purpose knowledge. Task specific knowledge exists at Levels 1 through 3, with Level 3 consisting of high level concepts, theory, and principles at one extreme, and Level 1 being highly compiled knowledge chunks and automated operators that do not require conscious attention at the other extreme. As tasks are repeatedly performed, task knowledge gradually transforms from higher levels to lower levels through a process known as knowledge compilation (Neves \& Anderson, 1981). The model predicts that informing between practitioners and academics will tend to be highly problematic. The reason given is that a practitioner problem space tends to be dominated by Level 1 knowledge, brought about by frequent repetitions of a relatively limited number of task situations (task cases). The academic problem space, on the other hand, tends to be dominated by Level 2 knowledge; studying a task will not produce the same type of knowledge compilation as repeatedly performing it, but such conceptual knowledge gained from systematic study is likely to be applicable to a broader set of task cases. This difference is illustrated in Figure 2 . 


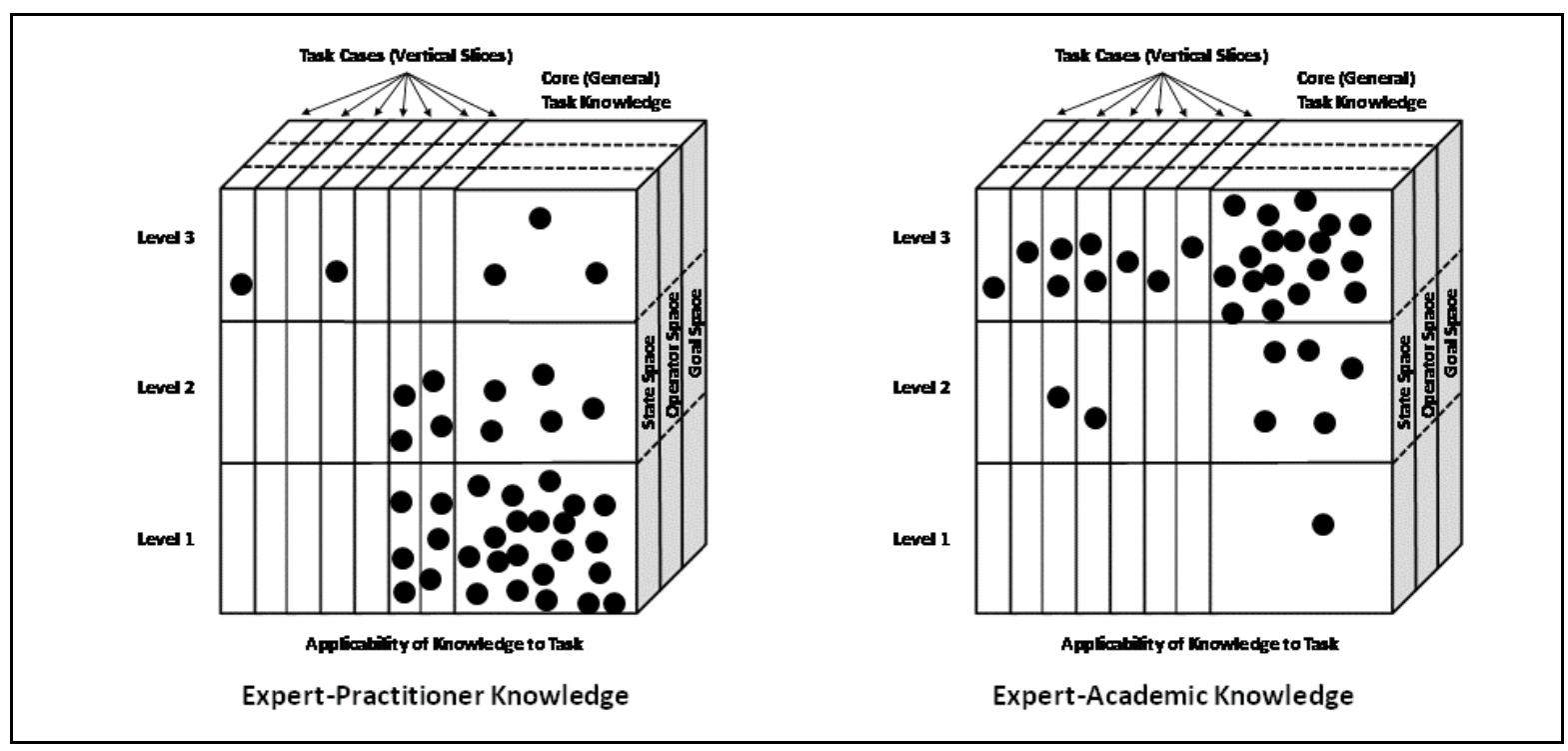

Figure 2: Practitioner versus Expert Knowledge (from T. G. Gill, 2008c), showing how practitioner task knowledge tends to be much more highly compiled than academic knowledge.

Informing systems design is another area where resonance-related concepts appear. A recent research stream applies philosophical perspectives, drawn from schools such as hermeneutics and phenomenology, to the informing system design process. Rather than perceiving informing as a straightforward process by which information is transferred, these schools emphasize parallel processes of knowledge acquisition and reflection/sense-making that continually interact, sometimes visualized using the metaphor of a double helix (Bednar \& Welch, 2007; Nissen, 2007). In such systems, users not only become involved in system design, but that involvement becomes an integral facet of the community in which they exist (Pang \& Shauder, 2007). Thus, the client-toclient element of resonance is emphasized. The objectives of information systems design processes also differ under such a model, emphasizing paying greater attention to the user's existing mental models and supporting user patterns of action (a.k.a., praxis) as opposed to strictly focusing on the usability of the system (Whittaker, 2007). What these models suggest is that in informing activities and in designing informing systems, a narrow-minded focus on the task at handone that ignores existing practices and the community in which the task is being performed-is unlikely to lead to effective informing. Once again, the conclusion asserts that meeting the prerequisites of rigor and relevance cannot ensure that resonance will be achieved.

\section{Single Client Resonance Model}

In the naval gunfire case study, it was pointed out that there were two types of moderators (in the case example, barriers) to informing: issues relating to the client's existing mental models and issues relating to the client's motivation. In considering how informing impacts the client, we synthesize the findings from three sources: the gunnery case presented earlier, the structural complexity model (T. G. Gill, 2008c) and the bias filter model (Jamieson \& Hyland, 2006). In performing this synthesis, we make three assumptions:

1. Because the problem space levels and forms of learning can be quite different in character, the nature of the filters that impact resonance may differ significantly. We therefore consider each level separately.

2. The bias in the filter model can work in three ways: it can change information passing through the channel, it can inhibit specific information flowing through the channel, or it 
can amplify information disproportionately to competing information. All three filter actions produce distortion.

3. Unless otherwise stated, we assume that the sender's intent is to convey information as accurately possible to the client. From time to time, however, we also recognize that the distortion created by these filters may be intended by the sender, used as a tool for manipulating the client.

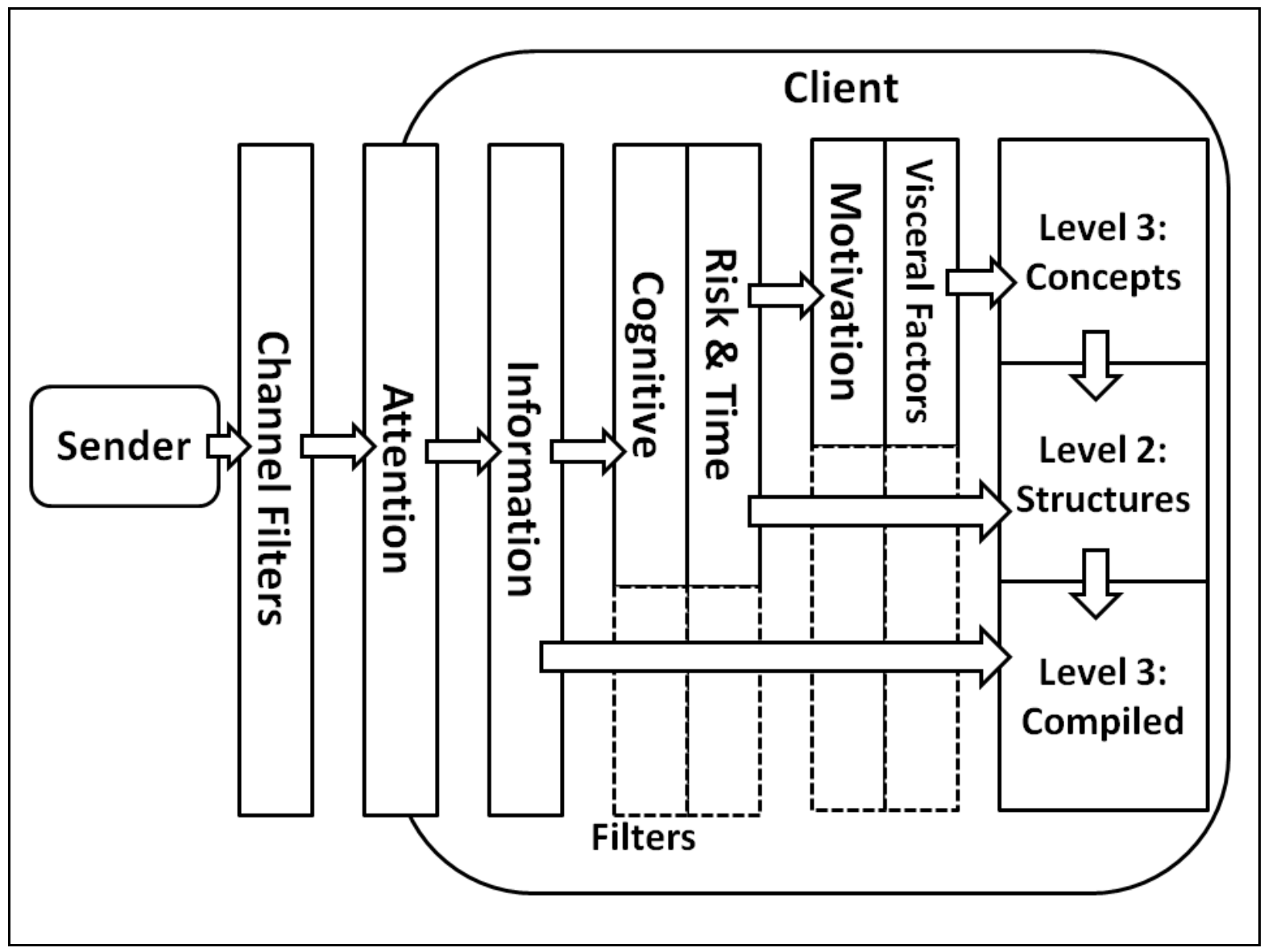

Figure 3: Client Resonance Model

To achieve a consistent synthesis, as illustrated in Figure 3, we start with the original bias filter model (Jamieson \& Hyland, 2006) and make the following modifications:

- We add an attention filter at the input to the client. As suggested by the naval gunnery case, the initiation of informing by the sender does not guarantee processing by the client - the message may just be ignored. This filter, it is assumed, will depend heavily on motivational and visceral elements of the informing situation.

- We treat uncertainty as part of the structural model, rather than as an explicit filter. The structural complexity model itself incorporates the notion of uncertainty directly-both through its state, operator and goal space levels and through uncertainty levels characterized for each state.

- The "risk biases" filter is generalized as the "risk and time preference" filter. This reflects the fact that attitudes towards risk and time often lead to similar effects and anoma- 
lies (T. G. Gill, 2008a). It is also consistent with some biological evidence that delayed and uncertain outcomes employ a great deal of common circuitry in the brain (Politser, 2008, p. 54). It is shown as adjacent to the cognitive filter because there is no particular reason for assuming one form of filtering will occur prior to the other.

- A motivation filter is added. This filter specifically addresses the aspects of the motivational context of the informing that are directly related (i.e., intrinsic) to the task that is the object of the informing.

- A visceral factors filter is added. This filter addresses motivational issues that extend beyond the task and, more generally, to the overall impact in informing of visceral factors, which include drives (e.g., hunger, thirst), moods, emotions, and pain. It is placed adjacent to the motivation filter because, once again, no particular ordering can be assumed with respect to motivational versus emotional filtering.

In addition to the changes within the client system, we explicitly recognize filters exist that are best viewed as being a property of the informing channel. It should be self-evident that channel capabilities - media richness (Daft, Lengel, \& Trevino, 1987), interactivity, time delays, capacity limitations - can exert a powerful influence on the nature of informing. Suppose, for example, you were a sender whose goal was to inform the client about the emotional impact of the Mona Lisa. If you were employing a broadcast text channel — such as a list server-there would be significant limitations on what types of information you could convey. To get around that you might relate studies regarding the nature of that impact, describe techniques employed by da Vinci to achieve such impact, and you might even describe its personal impact on you. The nature of the informing process would change dramatically, however, were a richer channel available. You might choose to present a high-resolution picture of the work. You might show video clips of tourists being affected as they viewed the painting at the Louvre. You might also cite the previously studies as well, of course. Thus, the choice of channel - which may be a decision of the client, the sender, or a mutual decision - can exert a powerful influence on the nature of the informing message. While channel selection is not the central focus of the present paper, which is specifically directed towards modeling client-side processes, it will need to be mentioned from time to time, since channel choice can impact other aspects of the informing process. Indeed, it is probably a mistake to get too comfortable treating the behavior of any element of an informing system as being independent from the remaining elements. Informing systems tend to exhibit many attributes that imply non-decomposability, otherwise referred to as rugged fitness landscapes (T. G. Gill, 2008b). In such systems, behaviors observed in isolated components often change substantially when observed in the context of the complete system.

We now explore the behavior of the single client resonance model. We do so first by considering how the filters are impacted by existing mental models. Next, we consider how intrinsic motivation - that is, motivation that is specifically related to the task around which informing is taking place - influences resonance. Finally, we consider the range of impacts on resonance that may be expected in the presence of visceral factors, with a particular emphasis on the role of emotions.

\section{Resonance and Mental Models}

In considering how resonance is impacted by pre-existing client knowledge, it is useful to specify what is meant by the term "mental model". For the purposes of the present paper, a relatively simple schema-based model will suffice - since the majority of research relating to cognitive issues surrounding learning generally employs a similar perspective. In this model, knowledge is

represented by schemata which are, in essence, objects possessing attributes (that may themselves be schemata). Over time, simple schemata may combine into more complex schemata through a 
process referred to as chunking (Miller, 1967), thereby allowing limitations on the number of available objects in working memory to be overcome. In such a model, three qualitatively different forms of learning are implicit (Rumelhart \& Norman, 1981, p. 335):

1. Accretion: the process of incorporating new information into existing schemata.

2. Tuning or schema evolution: The gradual process of refining existing schemata.

3. Restructuring or schema creation: The process by which new schemata are created. It may also apply to situations where existing schema are radically reconfigured, as would be the case where an existing mental model is replaced by a new one.

These forms also map well into a structural complexity model (T. G. Gill, 2008c), with restructuring being the most likely means for transforming conceptual schemata (Level 3), and accretion leading to incorporating information into existing compiled schemata (Level 1).

\section{Accretion}

The process of accretion has been described as "the most common and least profound sort of learning" (Rumelhart \& Norman, 1981, p. 336). The accretion involves bringing information into existing schemata, roughly comparable to filling in values on an incomplete form. Because the cognitive demands imposed by accretion-based processes are likely to be limited - task knowledge at the accretion level tends to be highly compiled - the most likely barrier to informing is the distortion of incoming information specifically associated with the information biases filter.

Many of the information biases that have been proposed appear to have a strong motivational character. For example, desirability bias, optimism, outcome bias, and wishful thinking (Russo, Meloy, \& Medvec, 1998) all have their origins in what the informing client wants to be true, rather than what necessarily is true. These will be discussed when we later consider the subject of resonance and motivation. There are, however, equally pervasive barriers that distort information, often unconsciously, based upon the client's existing task knowledge. Examples of these are now considered.

Judgment by Representativeness (e.g., Teigen, 2004). Representativeness is a mental shortcut that we use to avoid the need for extensive data gathering. It involves acquiring a small amount of information that is then mapped to some pre-existing schemata - a representative case-after which we base our actions and conclusions based upon the representative case. Such a phenomenon is likely to be most pronounced where task expertise is high, since the availability of representative examples will tend to be greater. Consider the following example:

You observe a person on the pavement who appears to be talking to himself. He is alone but smiling and gesturing. You decide that he is probably crazy. (Teigen, 2004, p. 165)

This example also illustrates the dangers inherent in representativeness. If an additional piece of information is provided or observed - that the individual was wearing a cellular phone ear piece-we might reach a radically different conclusion. Indeed, viewed in the context of a later time period (e.g., 2008 vs. 2004), many of us might have jumped to the cellular phone conclusion initially - since most of us have probably already observed such behavior.

The danger inherent in the representativeness bias is its inhibiting effect on informing; it tempts the client to end the informing process even though additional information gathering is warranted prior to drawing a rigorous conclusion. Indeed, representative issues first emerged in the context of individuals drawing statistically invalid conclusions from a small set of observations (e.g., Tversky \& Kahneman, 1982b).

Availability (e.g., Reber, 2004). Availability is characterized as making decisions based upon that information that is readily available to the task performer. Since availability, in turn, can be influ- 
enced by salience (i.e., how vivid the information is) and recency (Tversky \& Kahneman, 1982a), judgments that are based on availability can be significantly influenced by factors that are outside of the domain of the task. The availability effect can work in two ways. First, it can occur in conjunction with representativeness; readily available examples become the most likely to be accessed as being representative. Second, it can lead to a pronounced recency effect - also known as the serial position effect (Frensch, 1994) - in which the client recall for information acquired at the beginning and end of the informing process is amplified in comparison with that information transferred in the middle of the process.

Confirmation Bias (e.g., Oswald \& Grosjean, 2004). Clients tend to search for and interpret information that confirms their existing schemata. As a consequence, as a sender provides information that is similar to, but slightly different from, the client's own mental models, the client is likely to interpret it as being entirely consistent with those models. This bias also serves to amplify the impact of information consistent with the clients existing models.

Collectively, these representativeness, availability, and confirmation effects directly impact the validity of the changes made to the client's internal mental models during the informing process. Perhaps more importantly, they may prevent the client from recognizing situations where existing schemata are inadequate. As a result, they may inhibit schema evolution or restructuring in contexts where the nature of the task warrants these higher levels of informing.

\section{Tuning and Schema Evolution}

Schemata tuning and evolution is the orderly process by which new and revised representations are gradually added to the client's problem space. Such a process is likely to place considerably more cognitive demands on the client and, as a consequence, filters that reduce cognitive load are likely to play a larger role. Thus, we need to consider both cognitive and information filters at this level.

As a starting point, we should recognize that filters playing a role in accretion are also likely to play a role in schemata evolution. Indeed, it has been proposed that many information and cognitive heuristics - originally conceived of as biases and illusions - actually work quite well in those situations where there is a genuine need to economize on processing (e.g., see Table 4.1, Gigerenzer, 2004, p. 66). These filters can, however, inhibit the client's recognition of the need for new schemata, as previously noted. Filters that seem particularly relevant to the tuning and evolution level are now considered.

Recognition Heuristic (Gigerenzer, 2004). Information leading to schema evolution is likely to include a mixture of familiar and unfamiliar content (otherwise it could be handled through accretion). The recognition heuristic posits that when the two forms of information are comingled, the recognized information will play a much greater role in subsequent decision-making. An interesting demonstration of this heuristic occurred when separate groups of U.S. and German students were asked the question "Which city has more inhabitants: San Diego or San Antonio." Most U.S. students got the answer correct. What was more remarkable was the performance of the German students:

...most Germans know little about San Diego, and many have not even heard of San Antonio... Despite a considerable lack of knowledge, 100 percent of the Germans answered the question correctly. How can people who know less about a subject nevertheless make more correct inferences? The answer is that the Germans used a fast and frugal heuristic: the recognition heuristic: If you recognize the name of one city but not the other, then infer that the recognized city has the larger population. The Americans could not use that heuristic because they had heard of both cities... (Gigerenzer, 2004, p. 68) 
The obvious challenge that such a heuristic presents to the sender is in dealing with circumstances where the nature of the information that will be recognized by the client is unknown. In such situations, recognition could play a large role in client interpretation that is entirely outside of the sender's intent.

Choice strategies (e.g., Payne, Bettman \& Johnson, 1993). A wide range of strategies specifically designed to reduce the cognitive load of choice problems has been observed or proposed. In such problems, clients are presented with a set of alternatives, each of which has attributes that impact an alternative's attractiveness. Some of the most important choice heuristics (adapted from the list provided by Payne et al., 1993, p. 25-29) include:

- Equal weight heuristic (Einhorn \& Hogarth, 1975): Alternatives are compared across all relevant attributes, with each attribute being given an equal weight.

- Satisficing (Simon, 1955): Alternatives are considered until a pre-determined or adaptively determined cut point for fitness is reached.

- Lexicographic heuristic (Tversky, 1969): Alternatives are compared across the most important attribute and only those at the top are retained. Then the second most important attribute is considered and the process continues until only one alternative remains.

- Elimination by aspects (Tversky, 1972): Similar to lexicographic comparison, alternatives are compared across the most important attribute and only those meeting a desired cut point are retained. Then the second most important attribute is considered and the process continues until only one alternative remains.

- Majority of confirming dimensions (Russo \& Dosher, 1983): Alternatives are pair-wise compared attribute by attribute and the choice with the greatest number of winners is retained for comparison with the next alternative.

- Frequency of good and bad features (Alba \& Marmorstein, 1987): The positive and negative attributes of each alternative are counted. Choice can then be made based on the fewest number of bad features or the largest number of good features.

If a client is using such heuristics, then a number of sender-related decisions, such as the order in which alternatives are presented (particularly for satisficing) and the nature of information communicated about each option can exert a strong - and possibly unintended - impact on client task performance. For example, the sender's choice to emphasize quantitative or qualitative information may exert a significant influence on these heuristics and on the ultimate decision (Brindle, 1999). Here, once again, the nature of the channel employed may further impact choice through the informing process. Consider, for example, how the role of the real estate agent (sender) has changed in the real estate industry as the richness of the Internet-based real estate informing channels has grown and how the client's (buyer's) activities in the choice process has changed as a result.

Risk and Time Preferences. Risk and time preferences can interfere with informing when the sender's perception of or attitudes towards risk and timing differ from those of the client. For example, an alternative that appears sensible to risk-neutral, return-maximizing sender, such as a consultant, could be perceived quite differently and rejected out of hand by a risk-averse client. This could prove to be a significant barrier to informing across levels within an organization since the attitudes towards risk may systematically vary across the levels of an organization, with higher levels generally exhibiting greater risk tolerance (March \& Shapira, 1987). As a consequence, 
the communication of risky strategies devised by top management may be attenuated during the process of informing middle and lower management. A similar case can be made for time horizons that differ between sender and client. Informing an employee about the importance of acting in accordance with an organization's long term strategic goals may not be terribly effective if the employee is already planning to leave the organization and return to school.

\section{Restructuring or Schema Creation}

Where informing requires the creation of new knowledge or major restructuring of existing knowledge, the potential for informing filters and motivation effects to influence the client is at its peak. Some of the message distortion that can occur as a result of cognitive filters is now considered.

Learning by analogy (e.g., Rumelhart \& Norman, 1981). Where information being conveyed requires new knowledge structures, existing knowledge structures from different domains are often enlisted as part of the learning process. This is process is referred to as learning by analogy. This powerful technique allows us to leverage expertise from one domain and apply it to another. Unfortunately, our ability to recognize appropriate analogies is imperfect. This assertion is supported by research in which isomorphic problems were created specifically so as to allow subjects to take knowledge from one situation and apply it to another. For example, in an experiment where various tasks were created so as to be identical to the "Tower of Hanoi" puzzle (which subjects had previously learned to solve) the results were disappointing:

In fact, any of the problems could have been solved by mapping it into the Tower of Hanoi problem and then solving the latter. No subject did this, and only two or three even thought of trying or noticed the analogy. The problems, then, were identical in formal structure, but different in their "cover stories". (Simon \& Hayes, 1976, p. 478)

The problem that analogy creates from the sender's perspective is that the client's base of expertise outside of the task at hand will almost certainly be unknown. As a result, given the inconsistency of the analogy process, it may be very difficult to predict what analogy the client will use in constructing his or her new schemata. Thus, distortion between sender intent and client interpretation can easily arise.

Framing (e.g., Soman, 2004). A framing effect occurs where the particular presentation of a problem has a significant impact on the client's preferences or solutions. A common way to demonstrate framing issues is to take advantage of the asymmetry between gain and losses observed for most individuals (T. G. Gill, 2008a), with greater sensitivity to losses than to gains. Thus, a problem presented as an initial state followed by an opportunity to gain is more attractive than an initial state followed by a risk of losing. Consider, the following example (presented in T. G. Gill, 2008a where it was adapted directly from Tversky \& Kahneman, 1988, p. 173-174):

First choice problem:

Assume yourself richer by $\$ 300$ than you are today. You have to choose between:
A. A sure gain of $\$ 100$
B. $\quad 50 \%$ chance to gain $\$ 200$ and $50 \%$ to gain nothing

Second choice problem:

Assume yourself richer by $\$ 500$ than you are today. You have to choose between:
A. A sure loss of $\$ 100$
B. $\quad 50 \%$ chance to lose nothing, $50 \%$ to lose $\$ 200$ 
The actual results of this experiment were that most (72\%) chose $\mathrm{A}$ in the first problem, while most $(64 \%)$ chose $B$ in the second. This distinct preference is purely a result of framing since options A and B across both choice problems lead to precisely the same outcomes: a $\$ 400$ gain for option A, a 50-50 distribution between $\$ 300$ and $\$ 500$ for option B.

The structural complexity model proposes that cognitive framing (along with other effects such as anchoring) results from the use of generic goals to address unfamiliar problems (T. G. Gill, 2008a). As a consequence, framing-related distortions that occur in informing relationships are likely to be most commonly observed where restructuring and schema creation are involved. Once an individual recognizes the likelihood of framing occurring, it can be compensated for. Such recognition should come with experience, although this may be better described as a hypothesis than an assertion (T. G. Gill, 2008a).

Anchoring (e.g., Mussweiler, Englich, \& Strack, 2004). Anchoring effects are similar to framing effects; they occur when some initial value or alternative encountered in the task-often relatively arbitrary in nature-impacts subsequent decision making. These effects can influence decisions in two ways: 1) they may present the sender a means of manipulating client preferences and decision making or 2) they may lead the sender to influence client preferences and decisionmaking inadvertently.

Anchoring frequently occurs as a consequence of detecting favorable comparisons and similar options among choices. Common effects involving three or more options include (Usher \& McClelland, 2004):

- Attraction: Where three options are presented to a decision-maker and two are similar, with one clearly dominating the other, decision-maker preference tends to skew towards the dominant option in the pair, regardless of the characteristics of the third.

- Similarity: Where three options are presented and two are similar (with neither dominating), decision-maker preference skews towards the third, non-similar option.

- Compromise: Where three options are presented and one option could be viewed as a compromise between the other two, that option is disproportionately selected.

Illustrative examples of these types of effects abound in consumer marketing. For example, the "decoy effect", a variation of attraction, involves using one product model to anchor perceptions of another model. Consider the following example:

When Williams-Sonoma first introduced a home "bread bakery" machine (for \$275), most consumers were not interested. What was a home bread-making machine anyway? ... Flustered by poor sales, the manufacturer of the bread machine brought in a marketing research firm, which suggested a fix: introduce an additional model of the bread maker, one that was not only larger but priced about 50 percent higher than the initial machine.

Now sales began to rise... [Consumers] could say, "Well, I don't know much about bread makers, but I do know that if I were to buy one, I'd rather have the smaller one for less money." And that's when bread makers began to fly off the shelves. (Ariely, 2008, p. 1415)

In this example, the anchoring effect was specifically used to the sender's advantage. It could, in fact, be construed as a manipulation of the client's cognitive system. 


\section{Resonance and Intrinsic Motivation}

Whereas pure mental model effects most likely result in distortion of information transferred during the informing process, motivational effects can lead to failure to attend to a channel or to outright rejection of the message being transmitted. In this section, we consider the potential of intrinsic motivation - that is, motivation arising from the task itself - to influence informing. Visceral influences that fall outside of the task are addressed later, in the next section.

\section{Utility, Motivation, and Informing}

When economists and decision scientists attempt to assess the value of informing, the first concepts they typically introduce are uncertainty and utility (e.g., Hirshleifer \& Riley, 1992). The conceptual model then presented is that informing reduces uncertainty, which provides value to the client through increasing utility. Utility, in turn, is a measure of satisfaction that economists use to explain choice behavior. When presented with a series of alternatives, the rational decision maker chooses the alternative that maximizes utility. Because economists are principally concerned with economic returns, utility is generally viewed to be treated as a function of monetary returns, adjusted for risk, timing, and diminishing returns (T. G. Gill, 2008a).

While the economic utility model serves economists well enough, it is filled with inconsistencies when investigated from a psychological perspective. Human decision makers do not generally exhibit rationality of the sort that is axiomatic in utility-based models. Indeed, many of the issues discussed in the present paper-such as framing, anchoring, and satisficing - lead experimental subjects to exhibit preferences inconsistent with even the most plausible axioms, such as indifference between alternatives leading to identical outcomes.

A utility model has recently been proposed that is based upon more plausible psychological principles (T. G. Gill, 2008a). This model is grounded in the large management goal setting literature concluding that individual motivation arises from the pursuit and satisfaction of individual goals (Bandura, 1991). Motivation is closely related to utility, since we are most motivated to take the action that leads to the highest utility (T. G. Gill, 2008a). It therefore follows that -in the singleclient informing model - the type of utility that we should be concerned with maximizing in informing relationships is going to be heavily driven by the client's goals. These goals may or may not be economic in nature.

Naturally, economic goals can play an important role in informing. But humans have many other goals that may be of equal or greater importance. Performance goals represent the individual's intrinsic drive towards exemplary performance on a given task independent of monetary rewards. Mastery goals represent the individual's desire to improve his or her knowledge. Both types of goals are common in informing settings, such as universities (Elliot \& Harackiewicz, 1996). Individuals are also motivated by the desire to achieve control over activities (Gilbert, 2007; Thompson, 2004). Finally, social and altruistic goals (Simon, 1992) may play an important role in motivation. To ignore the role played by non-monetary client and sender goals in the informing process is to ignore one of the key factors that can derail informing. As illustrated in the naval gunnery case study, once the client's motivation to be informed is lost, the entire process can collapse and alternative channels will need to be found.

We now consider some specific examples of motivation-based issues that can impact informing. As also illustrated by the naval gunnery case, these motivational issues tend to exert an impact in two ways: by affecting the client's willingness to attend to the channel (attention filter) and by affecting the client's willingness to alter existing mental models to accommodate the new information being received (motivation and visceral filters). Such motivation, however, will derive from two separate sources: factors intrinsic to the informing-related task and factors extrinsic to that task (to be covered in the next section which considers visceral factors, as previously noted). 
As an organizing framework for the intrinsic factors, we'll use the three categories of task-related intrinsic motivation identified in a study of expert systems (T. G. Gill, 1996): performance, arousal, and control.

\section{Performance, Mastery, and Abandoned Expertise}

The first category of intrinsic motivation to be examined relates to performance. From an informing perspective, it can impact both client willingness to attend to the channel and willingness to change existing mental models.

Overconfidence (e.g., Hoffrage, 2004). Individuals, including experts, tend to be overconfident in their own knowledge. A natural consequence of this is inhibiting information flow; a client may terminate or cease attending to an informing process before all useful information has been transferred.

Conceptually, the structural complexity model would expect overconfidence to be most pronounced at the knowledge structure level, rather than the concept level. At the higher levels of structural complexity (Levels $3 \& 4$ ), client goals will tend to form a complex, multi-peaked fitness space (T. G. Gill, 2008c). In such an environment, excessive confidence should be less likely to develop. As the client acquires expertise, moving down to Level 2, specialization upon specific, well-defined goal peaks will tend to occur. That will lead to both substantially improved task performance and a tendency to lose sight of other peaks, referred to as the Law of Limited Visibility (T. G. Gill, 2008c). As a result, the client's new-more expert-perception of the task being performed is reinforced. Such an evolution will lead to increased, and perhaps excessive, confidence.

A number of other observed phenomena are consistent with the more narrow view of the task that comes with practitioner expertise. One example is the escalating commitment effect (Jamieson \& Hyland, 2006), where a promising alternative is given increasing amounts of attention until the point at which no other alternatives are being considered. Another is the single outcome calculation (Jamieson \& Hyland, 2006), where a widely shared criterion is used to create a consensus for a particular decision without giving full consideration to other alternatives. Both of these would motivate the client towards premature termination of informing.

Law of Abandoned Expertise: Psychologists have long known that individuals are motivated to achieve high performance, irrespective of whatever rewards may be received. Many individuals are similarly motivated by the process of achieving mastery over a particular domain of knowledge (Elliot \& Harackiewicz, 1996). Once an individual has achieved expert status, performance becomes nearly effortless - thanks to knowledge compilation, the cognitive demands of the task are not overly great - and a sense of mastery is achieved. Based on this, we would expect individuals to prize their expertise and to be very reluctant to give it up. This phenomenon has been proposed in the form of the behavioral Law of Abandoned Expertise (T. G. Gill, 2008c):

Hypothesis: Clients will resist any task-related informing activities that require relinquishing existing expertise in their problem space.

Many different sources of evidence support the view that this law-if not always true-is at least true a great deal of the time. There are many examples of students who are remarkably unwilling to abandon their pre-conceived notions even in classes where graphic experimental demonstrations of the weakness of their prior beliefs have been presented (Bain, 2004). Scientists refuse to relinquish paradigms even in the presence of strong evidence that their view is incorrect (Kuhn, 1970). Pre-existing notions prevent the adoption of even simple procedures, such as boiling unsanitary water to avoid illness (Rogers, 2003). The behavior in the naval gunfire example clearly 
illustrated this law. How else can one explain the refusal of the Bureau of Naval Ordnance's to investigate further when Sims originally sent in his findings?

Obviously, we would expect the abandoned expertise phenomenon to be particularly severe where the sender is attempting to convey information to the client that is inconsistent with the client's existing concepts, theories, or practices. Unfortunately, practitioner and academic expert knowledge nearly always exhibit such inconsistencies owing to their fundamentally different structures (see Figure 2). This difference in mental models is proposed to be a major source of the deplorable state of academic-practitioner communications in some disciplines, such as management and MIS (T. G. Gill, 2008c).

\section{Arousal Motivation}

The next category of intrinsic motivator relates to arousal. From an informing perspective, it is most likely to impact the client's willingness to attend to the channel.

Unlike control and performance motivations, motivation for arousal is not unlimited. Although we may have a cognitive motivation for information seeking (Driver \& Streufert, 1969) and variety (Hackman \& Oldham, 1980), the cognitive demands of too much arousal can lead to stress, or even panic (Streufert \& Streufert, 1978), sometimes referred to as "information overload". As a consequence, the motivational character of arousal is generally plotted as an inverted-U, with desired arousal being an intermediate value that is not too great-leading to overload - but also not too low-leading to boredom.

Unexpected. Informing that falls within the appropriate arousal bounds will sometimes be termed interesting. In a widely cited article relating to the social sciences, Davis (1971) emphasizes that research, in order to be interesting, must contain an element of the unexpected. Research whose sole purpose is to support an existing paradigm may be useful, but it will not be interesting. Because unexpected information requires the creation of new structures, it will lead to greater client arousal than communicated concepts that are already incorporated within existing client models. The motivation for such arousal is not unbounded, however. As evidence of the inverted-U shape, Davis further argues that the sender can also exceed the client's capacity to accept the unexpected. In a statement that also supports the Law of Abandoned Expertise, he asserts:

Yet one must be careful not to go too far. There is a fine but definite line between asserting the surprising and asserting the shocking, between the interesting and the absurd. An interesting proposition, we saw, was one that denied the weakly held assumptions of its audience. But those who attempt to deny the strongly held assumptions of their audience will have their very sanity called into question. They will be accused of being lunatics; if scientists, they will be called 'crackpots'. If the difference between the inspired and the insane is only in the degree of tenacity of the particular audience assumptions they choose to attack, it is perhaps for this reason that genius has always been considered close to madness. (Davis, 1971, p. 343)

Distractibility. Another arousal-related phenomenon that impacts informing, at the opposite side of the scale from information overload, is distractibility. Human cognitive systems are not like the single-process computers of the 1950s and early-1960s. They often attend to a number of tasks concurrently, at different levels of arousal, and focused attention can shift from task to task in the event that optimal arousal levels are not being achieved in the most highly attended channel. Indeed, distractibility is so common and significant in its impact that one of the most serious criticisms that a cognitive scientist can make against any proposed model of cognition is that it does not account for the phenomenon (Newell, 1990, p. 227). 
One area where the nature of distractibility and attention has been studied extensively is in the advertising industry, where senders pay large sums of money to inform clients in a very short period of time. In one study (Lord \& Burnkrant, 1993), for example, researchers examined how the interest generated by program content interacted with the attention paid to commercials within the program. They found many levels of interaction between interest in the program, interest in the commercial, and use of an attention-grabbing device (audio beeps for the low involvement commercial for an oil product, a compelling visual image for the high involvement commercial involving drunk driving). The relationships they found were quite complex. For example, where program involvement was high, a high-involvement commercial combined with use of the attention grabbing device threatened to distract clients from the message. Low involvement commercials, on the other hand, benefitted from the high level of arousal carrying over from the highinvolvement program. On the other hand, where program-involvement was low a highinvolvement commercial fared better, and the attention grabbing device generally seemed warranted. The complexity of the results arising from this relatively simple stream of research suggest that it will be difficult to devise general principles for predicting how to format messages that garner optimal attention in the presence of distractibility.

Interference. Another aspect of arousal from an informing channel is its ability to interfere with other cognitive processes. An example of this can be found in teenage driving:

A recent study found that a teenage driver driving alone was 40 percent more likely to get into an accident than an adult. But with one other teenager in the car, the percentage was twice that — and with a third teenager along for the ride, the percentage doubled again.

(Ulene, 2007, as cited in Arielly, 2008).

In this example, the informing channels that interfered with the task were unrelated to the task. It is also perfectly plausible that - for some activities - the informing activities of the task could interfere with other cognitive activities of the task. For example, if a conference presentation is particularly engaging the moderator may forget to check the clock, thereby interfering with his or her assigned task of ensuring that subsequent presenters have a fair allocation of time.

\section{Control Motivation}

The final category of intrinsic motivators to be examined is control. From in informing perspective, it is most likely to impact client willingness to change existing mental models.

The sense of control over your activities and their outcomes is a powerful motivational force (Gilbert, 2007). Client motivation to be informed should therefore be impacted by whether or not the expected impact of the informing is greater client control over the task or less control. As an example, a study of expert system usage found a highly significant relationship between continuing use and the change in user discretion (i.e., control) that accompanied adopting the system (T. G. Gill, 1996). After controlling for the quality of system performance, where discretion increased, continued usage was high. Where discretion declined, far more systems were abandoned.

Illusions of Control (e.g., Thompson, 2004). Individuals frequently perceive that they have greater control over a task than is actually the case. For example:

...people bet more money on games of chance when their opponents seemed incompetent than competent - as though they believed they could control the random drawing of cards from the deck and thus take advantage of a weak opponent. People feel more certain that they will win the lottery if they can control the number on their ticket, and they feel more confident that they will win a dice toss if they can throw the dice themselves (Langer, 1975, and Dunn \& Wilson, 1991, as cited in Gilbert, 2007, p. 22) 
Where such a perception exists, we would expect that motivation to be informed will decline. Moreover, visceral influences also appear to exert an influence over this particular illusion: depressed people have a reduced sense of control, whereas individuals in a positive mood are more likely to experience this illusion. Similarly, individuals having a high level of desire for a particular task outcome tend to perceive that they have control (Thompson, 2004).

\section{Resonance and Visceral Factors}

Visceral factors include emotions and feelings-sometimes referred to collectively as affect within the psychology and management literatures - as well as drives (e.g., hunger, thirst, sex), moods, and pain (Loewenstein, 1996). These can play an important role in the informing process. Unlike performance, arousal, and control, however, many of the sources of visceral factors are not tied to the task-related content of the informing message or the task being performed.

Visceral factors have the potential to impact virtually every aspect of the informing process, and a full treatment of the subject is beyond the scope of this paper. Instead, we need to content ourselves with describing some of the mechanisms through which these factors, particularly emotions, may impact the informing process. Specifically, we consider:

- Impacts of visceral factors on cognitive functions

- Impacts of visceral factors on choice processes

- Impacts of anticipated emotions and feelings

- Impacts of social factors

We begin, however, by distinguishing what we mean by emotions and feelings.

\section{Emotions versus Feelings}

Prior to considering the impact of emotion and feelings on informing, it is useful to distinguish between the two. As illustrated in Figure 4, emotion is viewed as a psychological state, often brought on by an event. That psychological state, in turn, may induce physiological and cognitive changes. Our subjective perceptions of these changes become our feelings. As a result, in research where emotion levels are based upon self-reports, what is being observed can often more accurately be characterized as feelings. Although emotions and feelings are often lumped together, the distinction appears to have a physiological basis (Dolan, 2002).

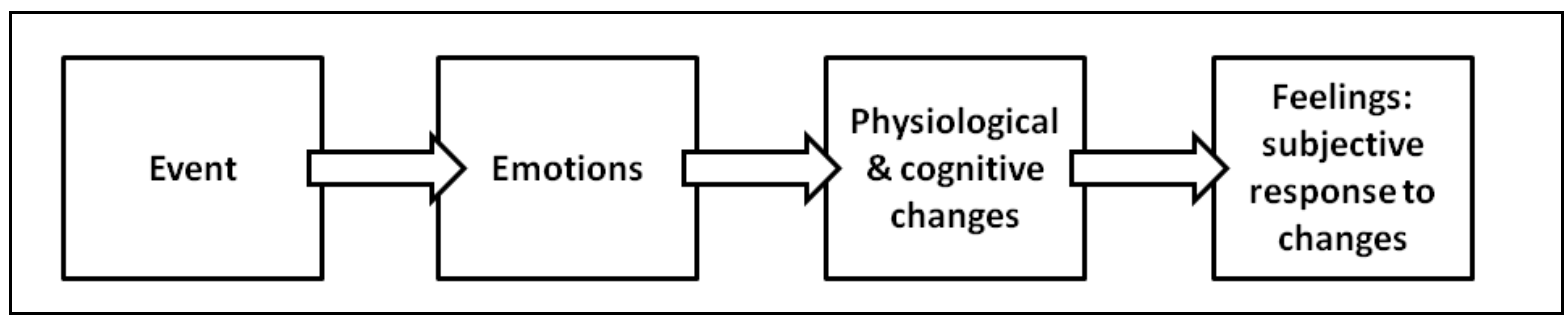

Figure 4: Emotions and Feelings

\section{Visceral Factors and Cognitive Functions}

Visceral factors have the ability to impact cognitive functions in many ways. Many of these resemble the task-related filters already discussed except that their source is extrinsic to the task. A number of the effects that have been observed are now described.

Emotions and information processing: Emotions can change the client's ability to process information. For example, a number of important emotion-related effects on information processing in the human cognitive system have been observed (Dolan, 2002): 
- Processing priority: Emotion-laden information cues appear to get a higher priority when compared with other sensory and cognitive cues.

- Enhanced memory of emotionally significant events: Conditioning experiments support anecdotal evidence that when emotionally significant events (e.g., the Challenger disaster) occur, they enter memory more effectively.

- Recalling past emotion-laden effects decision-making: Specifically, when such states are evoked they can bias decisions either towards or against similar decisions, depending upon the emotions recalled.

Interference. As was the case with arousal related to information flows, visceral and emotional arousal can interfere with cognitive functions, including those related to informing. In the presence of strong arousal from visceral factors, individuals will frequently and knowingly act in ways that are inconsistent with their own long term self interest (Loewenstein, 1996). A rather graphic demonstration of the impact of such factors occurred in an experiment that examined how sexual arousal influenced decision-making and judgment (Ariely \& Loewenstein, 2006). Subjects, in various states of physical arousal, were asked to rate their attitudes towards various questionable sex-related practices (e.g., safe sex, lying in order to get sex, continuing to pursue sex after a refusal). Uniformly, and highly significantly, their willingness to engage in questionable practices grew with their level of physical arousal.

The ability of visceral factors - in this case, anger - to interfere with informing was also amply demonstrated in the later stages of the naval gunnery case. By the time the process had degenerated into name-calling, it is doubtful that any informing was taking place, despite the fact that information was being transmitted.

In considering the impact of visceral factors, a number of propositions are advanced that are particularly likely to be relevant in a client-sender context (Loewenstein, 1996, p. 278):

i. We tend to become less altruistic than we would like to be when visceral factors intensify.

ii. When making decisions for another person, we tend to ignore or give little weight to visceral factors they are experiencing

iii. Increasing the intensity of a visceral factor for ourselves and another person in parallel leads to a decline in altruism.

iv. When we experience a particular visceral factor, we tend to imagine others experiencing it as well, regardless of whether they actually are.

v. People underestimate the impact of visceral factors on other people's behavior.

In the context of informing, this suggests that the sender will expect the client to be a rational party to the informing process even when the sender personally recognizes that visceral factors are influencing his or her own actions. The same would apply to the client's perception of the sender. Given the high potential for influence on cognitive processes of such factors, the failure to recognize their presence on either the client or sender side can present a serious barrier to informing. Like many other effects mentioned in this paper, this barrier could be considerably intensified in situations where channels of low media richness are employed. For example, discussion group trolling (Herring, Job-Sluder, Scheckler, \& Barab, 2002) and email flaming (Alonzo \& Aiken, 2004) both represent behaviors that interfere with effective informing. Both are posited to have a strong visceral component (e.g., Alonzo \& Aiken, 2004). Experience also tells us that similar disruptive behaviors occur much less likely frequently when a media-rich face-to-face channel is used. 
Priming. A particularly remarkable demonstration of the power of visceral influences and emotional state to impact cognition can be found in the phenomenon of priming (e.g., Gladwell, 2005). Priming occurs when mere exposure to certain words and behaviors prior to an activity exert a strong impact on subsequent performance of that activity. Experimental psychologists use priming frequently; it proves to be a very useful tool in laboratory studies where the impact of emotional state on cognition or learning is being tested. Numerous examples exist of the phenomenon, which can be astonishingly powerful in its impact. For example:

Two Dutch researchers did a study in which they had groups of students answer forty-two demanding questions from the board game Trivial Pursuit. Half were asked to take five minutes beforehand to think about what it means to be a professor and write down everything that came to mind. Those students got 55.6 percent of the questions right. The other half of the students were asked to first sit and think about soccer hooligans. They ended up getting 42.6 percent of the Trivial Pursuit questions right. The "professor" group didn't know any more than the "soccer hooligan" group. They were simply in a "smart" frame of mind... (Dijksterhuis \& van Knippenberg, 1998, as cited in Gladwell, 2005, p. 56)

Priming can also impact how we experience and disambiguate stimuli-a critical element in informing processes. For example:

...volunteers in one study were told that they would be eating a delicious but unhealthy ice cream sundae (ice cream eaters), and others were told that they would be eating a bitter but healthful plate of fresh kale (kale eaters). Before actually eating these foods, the researchers asked volunteers to rate the similarity of a number of foods, including ice cream sundaes, kale, and Spam (which everyone considered both unpalatable and unhealthful). The results showed that ice cream eaters thought Spam was more like kale than it was like ice cream. Why? Because for some odd reason, ice cream eaters were thinking about food in terms of its taste... On the other hand, kale eaters thought that Spam was more like ice cream than it was like kale. Why? Because for some odd reason, kale eaters were thinking about food in terms of its healthfulness... (Gilbert, 2007, pp. 159-160).

From a conceptual standpoint, priming effects are similar to framing and anchoring except that they occur entirely outside of the task being performed. As was the case for framing and anchoring, we'd expect the effects of priming to be most pronounced for less familiar activities. Also, particularly where the sender-client channel involves information technology and is not face-toface, the presence of client priming stimuli may well be unknown to and beyond the control of the sender.

\section{Emotions and Choice}

There are a number of visceral counterparts to the mental model effects of framing, anchoring, and choice strategies that have been observed. These seem to be particularly pronounced when emotions are involved, although we would expect that other visceral factors could exert a similar influence.

Emotional framing. Effects similar to framing may also be observed that have a distinct emotional component. We refer to these as emotional framing. One example involves the presence of money. Numerous experiments demonstrate that when money is involved, different preferences and behaviors are exhibited than if non-money equivalents are used and that such attitudes cross the line into non-economic contexts. Individuals, for example, are found to be much more likely to cheat when money is not directly involved (Ariely, 2008). The influence of money can also explain, for example, the widely observed phenomenon that consumers spend more when using 
credit cards than when using cash-even consumers who pay their entire balances each monthand why such spending further increases based on the size of unused credit limits (Soman \& Cheema, 2002).

Similar emotional impacts on rational decision making can be found in the phenomenon described as "auction fever" (Ku, Malhotra, \& Murnighan, 2005). As noted in the article:

In 1999, Chicago sponsored a public art exhibit of over 300 life-sized fiberglass cows that culminated in 140 Internet and live, in person auctions. Collectively, the cows sold for almost seven times their initial estimates. (Ku et al., 2005, p. 89)

The nature of the frenzy observed by the researchers caused them to attribute the unexpected valuations to competitive arousal, an emotional reaction to the auction process leading buyers to depart from intended behaviors.

Although the second of these examples could be attributed to the unfamiliarity of the situationhow often do most people purchase fiberglass cows at auction? - the first example, credit cards being used more freely than cash, cannot. Thus, it is quite plausible that the impact of visceral framing may extend to routine, as well as non-routine, decisions.

Emotional anchoring. Similar to framing, anchoring can occur on an emotional level, as well as on a purely cognitive level. In politics, for example, candidates frequently attempt to draw parallels between their own background and those of other loved politicians, at the same time noting distinctions between themselves and other hated politicians. A particularly famous example of this occurred in the 1988 U.S. presidential campaign, during the vice presidential debate. In prior speeches one candidate, Senator Dan Quayle, had often identified similarities between his own background and that of John F. Kennedy, whose tragic death in office still evokes a strong emotional response in many Americans. His opponent, Senator Lloyd Bentsen, aware of these past comparisons, waited for Quayle to make a similar comparison during a televised debate. When Quayle did, Bentsen then made the emotional response:

Senator, I served with Jack Kennedy, I knew Jack Kennedy, Jack Kennedy was a friend of mine. Senator, you are no Jack Kennedy. (Commission on Presidential Debates, 2004)

That statement completely negated the attempted anchoring, as well as becoming the most famous rejoinder ever made during a vice-presidential debate.

Emotions impact on choice strategies. Emotions have been found to play a direct role in decisions involving choice. For example, individuals who are given a set of alternatives and attributes find it more difficult to make trade-offs of emotion-laden attributes for money than less emotion-laden attributes (Luce, Payne, \& Bettman, 1999). There is also considerable evidence of the impact of emotional state on the perception of products and on the weighting placed on different product attributes (Adval, 2001). Viewed in the context of prospect theory-a cognitive model for evaluating uncertain and distant outcomes - emotions have been found to impact both perceived outcome values and the weight attached to uncertainty and time preferences when discounting (Rottenstreich \& Shu, 2004). As a consequence, emotions can, potentially, distort the informing process in much the same manner as purely cognitive choice heuristics. This is particularly true in situations where the sender is not cognizant of the client's emotions, as would be the case where non-rich media are used as the channel (Daft et al., 1987).

\section{Anticipated Feelings}

Emotions and feelings may be generated as a consequence of being informed. Where this is the case, the decision to engage in the informing process may be impacted by what the client expects to feel, rather than by what is actually felt. This effect may be amplified by the fact that antici- 
pated feelings are often far greater than the actual feelings that are later experienced (Gilbert, 2007), in which manner they differ from most of the other visceral factors (which tend to be underestimated).

Procrastination. One example of how anticipated emotions can impact informing involves procrastination. If the anticipation of poor performance or failure is strong, a client may avoid attending to the informing system. Consider, for example, the following explanation provided by a distance learning student for her failure to attend to the course syllabus:

What used to be a simple schedule and list of assignments, two pages at most, has become an intimidating document, often a dozen pages long, filled with mandatory administrative policies, honor codes, disability and religious accommodations, complex tables with Web links and even the occasional contractual agreement between instructors and students. Although I'm starting to learn about these things, I still have a strong flight reflex that leads me to avoid that which I cannot immediately understand and prevents me from actively seeking that which I do not want to know. (C. Gill, 2006)

Cheating. Cheating is another example of a behavior through which (desired) informing channels are not attended. One study that specifically examined the impact of anticipated emotions on willingness to cheat found that the anticipated elation associated with cheating was an important antecedent of willingness to cheat - much more so than anticipated regret (Sierra \& Hyman, 2006).

Refusal to be informed. Anticipated emotions can also play a powerful role in the refusal to learn. One particularly common version of this phenomenon is those situations where the client perceives that by accepting the information, his or her mental models will become at odds with prevailing models in the social network. In the opening example of Diffusion of Innovations (Rogers, 2003 , p. 1-5), a case study is presented of a Peruvian village in which existing mental models of health were based upon a dichotomy of "hot" and "cold", where "hot" was associated with illness and "cold" was associated with health. The attempts of a health worker to get the community to adopt the practice of boiling water to improve sanitation were largely unsuccessful. This was attributed to the fact that any individual following this practice would be at odds with the prevailing wisdom and behaviors of the community. Indeed, the two examples where the informing effort was successful were in the case of a woman who was already ill - and therefore expected to favor "hot" - and an outsider family, who had moved from another area where the hot-code dichotomy did not exist.

\section{Social Factors}

It is very likely that many of the examples previously cited as evidence for the Law of Abandoned Expertise also have social components that amplify the task-specific effect of the proposed law. We saw this demonstrated in the previous example of the Peruvian village. Similar examples closer to home are also readily available. The student who adopts models or behaviors at odds with his or her peers may be castigated. The scholar who is swayed by evidence that is contrary existing paradigms may become isolated from colleagues. The middle manager who comes to believe in an unconventional idea, however strong the evidence supporting that idea may be, risks losing credibility and stature in the eyes of both employees and executives.

Conceptually, we can view the social factors that impact motivation to be informed as being somewhat parallel in structure to the intrinsic motivational factors that operate at the task level (T. G. Gill \& Saunders, 1997). For example, the social constructs of power, dependence, and autonomy map well into control. Both performance and arousal can be viewed in a broader social context rather than being limited to the task itself. For example, the intrinsic benefits of mastery can easily translate into status in a social setting. The arousal experienced during many informing communications will likely have both an informational task-related component and a social com- 
ponent. Indeed, there is an entire category of job described as "emotional labor" (Morris \& Feldman, 1996) — which includes many types of customer service activities - for which conveying proper emotions and engaging customers in a personal way are considered more important than the associated information-conveying function of the job. How much the emotional and social aspects of informing will impact the client's willingness to change existing mental models is likely to depend heavily on the context of the informing. Nonetheless, if we fail to take into account our client's perspective on the anticipated emotional and social consequences of both the informing process and of being informed, the likelihood that informing will be disrupted or distorted in some fashion is great.

\section{Stickiness: A Unified Approach to Client Resonance?}

In The Tipping Point, Gladwell (2000) introduced the notion of a "stickiness factor" as being one of the three principal laws of change, later illustrating the concept with examples from children's television shows, such as Sesame Street and Blue's Clues-where explicit changes to design were implemented to increase their effectiveness in informing (child) clients. The concept of stickiness has been further expanded into a six item framework (Heath \& Heath, 2007), referred to using the acronym SUCCESs. The six contributors to stickiness are identified to be:

1. Simple: Messages should be as simple as possible.

2. Unexpected: Messages are more effective if they contain elements that the client cannot predict in advance.

3. Concrete: Concrete messages are more effective than abstract messages.

4. Credible: Message effectiveness increases with credibility.

5. Emotional: Messages with emotional content are more effective.

6. Stories: Stories are among the most effective form of message.

Stickiness has much in common with resonance. In particular, it emphasizes that the form of a message - as opposed to its specific content (i.e., quality, usefulness) — can exert a major influence on whether or not effective informing occurs. As an informal test, it is therefore useful to consider the degree to which the single client resonance model, presented earlier in Figure 3, maps into the SUCCESs framework. Remarkably, they not only seem to correspond quite well but also in order.

Messages that are simple and unexpected both stand the best chance of penetrating the attention filter. Simple reduces the likelihood of cognitive overload; unexpected makes them interesting (Davis, 1971). Concrete messages reduce the likelihood of distortion passing through the cognitive filter. The less a message is subject to interpretation, the lower the chance that representativeness and confirmation biases will transform the message into something that the client perceives to be already known. Credibility should reduce interference from the risk and time preferences filter and should also help motivate the client. Naturally, the emotional content of the message maps to the visceral filter.

So where do stories come in? In the structural complexity model, as illustrated in Figure 2, three general modes of acquiring expertise are posited (T. G. Gill, 2008c). The top down mode, as exemplified by lecture style teaching, builds knowledge from the concept level down - structures and compiled elements are driven by theory. In the bottom up mode, as exemplified by constructionist learning approaches, the client is provided with information about situations and is then guided through the process of developing his or her own individualized concepts and models. The third mode is the vertical-slice mode, as exemplified by the example-problem driven approach to teaching that is often applied in the sciences. In this approach, relatively complete problem spaces are presented as a sequence (i.e., the task cases in Figure 2) that gradually increases in difficulty and realism. Such an approach is posited as being particularly appropriate for communicating 
with practitioner experts, since it allows informing to be conducted in the form of "new examples" that do not directly threaten the practitioner's existing base of expertise.

A story can be viewed as a vertical slice of a problem space, conveying state, goal, and operator information in a single compact package. As such, it should be a versatile tool for any informing situations where the vertical slice approach is warranted. Indeed, it should be particularly valuable in informing practice for the reasons already given. In business, this conjecture appears to be supported by the composition of journals aimed towards practitioners. The Harvard Business Review, for example, uses stories and anecdotes as its principal-and, frequently, only - source of evidence (e.g., Rynes, Giluk, \& Brown, 2007, p. 999) and has published articles on the value of story-telling (e.g., Guber, 2007).

Given the elegance and simplicity of the SUCCESs model, along with its correspondence to the filters of the single client resonance model of Figure 3, the reader would do well to question why we should bother with new model at all. The justification involves an important difference in purpose. The SUCCESs model is particularly focused on situations where an informing process targets many clients in parallel, as is the case with mass media. For this reason, it is designed to encapsulate the general principles that apply to all clients. In this respect it performs admirably; there is not a single element of the SUCCESs model that does not apply to almost any real mass communication situation.

The single client resonance model, on the other hand, is designed around the informing system. In such a system, we are likely to have an in-depth understanding of the task to be performed andin many cases - a reasonable sense of the mental models of the individuals who will be performing that task. As a consequence, it can (and needs to) address many issues that may vary on an individual client basis. With increasing sender-task-client-specificity comes the need for increasing comprehensiveness in what we consider. Given the inherent nature of the general informing system - requiring the melding of the needs of the sender, the technologies that support the channels, and the client - it is doubtful that a general set of principles as compact as the SUCCESs model will ever be developed. If, as researchers, we are ever going to contribute to the general understanding of these systems, we must accept that the complexity of the endeavor that we have chosen to investigate will prove an ever-present and formidable obstacle.

\section{Conclusions}

For about half a century academic researchers in business - and other disciplines as well - have been debating whether our research should be focusing on rigor or relevance. In engaging in that debate, many of us seem to have lost sight of the fact that how we inform our clients of what we have done is likely to be just as important a factor in impacting our clients as the quality (rigor) and potential usefulness (relevance) of what we have discovered. The informing sciences are uniquely positioned to bring this message to the research community.

The single client resonance model proposed in this paper is probably better characterized as a research agenda than a theory. What it attempts to do is to organize a large number of observations, almost none of which were gathered with the study of informing in mind, into a theory-based framework that helps clarify what we know, what we suppose, and where we are still largely uncertain. As more systematic research is conducted and more perspectives are gathered, the contents of the framework will doubtless grow and need modifications. As research is conducted in areas where we are unsure, perhaps we will be able to reduce the amount of uncertainty that remains.

As we look forward towards future research, it is important to recognize that the single client resonance process considered in this paper is not the only form of resonance we need to consider. A vast body of diffusion research (e.g., Rogers, 2003) suggests, to the contrary, that where the in- 
forming needs are great and the number of clients is great, the clients themselves will act as the means through which most informing will take place. That does not make achieving single client resonance any less important. Diffusion has to start somewhere. If we cannot achieve resonance with the individual client, the informing process cannot begin.

\section{References}

Adval, R. (2001). Sometimes it just feels right: The differential weighting of affect-consistent and affectinconsistent product information. The Journal of Consumer Research, 28(1), 1-17.

Alba, J. W., \& Marmorstein, H. (1987). The effects of frequency knowledge on consumer decision making. Journal of Consumer Research, 14, 14-26.

Alony, I., Whymark, G. \& Jones, M. (2007). Sharing tacit knowledge: a case study in the Australian film industry. Informing Science: the International Journal of an Emerging Transdiscipline, 10, 41-59 Retrieved from http://inform.nu/Articles/Vol10/ISJv10p041-059Alony360.pdf

Alonzo, M., \& Aiken, M. (2004). Flaming in electronic communication. Decision Support Systems, 36, 205-213.

Ariely, D. (2008). Predictably irrational. New York: Harper Collins.

Ariely, D., \& Loewenstein, G. (2006). The heat of the moment: The effect of sexual arousal on sexual decision making. Journal of Behavioral Decision Making, 19, 87-98.

Bain, K. (2004). What the best college teachers do. Cambridge, MA: Harvard University Press.

Bandura, A. (1991). Social cognitive theory of self-regulation. Organizational Behavior and Human Decision Processes, 50, 248-287.

Bednar, P., \& Welch, C. (2007). A double helix metaphor for use and usefulness in informing systems. Informing Science: the International Journal of an Emerging Transdiscipline, 10, 273-295 Retrieved from http://inform.nu/Articles/Vol10/DblHelix273-295.pdf

Brindle, M. (1999). Games decision makers play. Management Decision, 37(8), 604-612.

Cohen, E. (1999). Reconceptualizing information systems as a field of the transdiscipline informing science: From ugly duckling to swan. Journal of Computing and Information Technology, 7(3), 213-219.

Commission on Presidential Debates. (2004). The Bentsen-Quayle vice presidential debate. Retrieved on 6/2/2008 from http://www.debates.org/pages/trans88c.html

Daft, R. L., Lengel, R. H., \& Trevino, L. K. (1987). Message equivocality, media selection, and manager performance: Implications for information systems. MIS Quarterly, 11(3), 355-366.

Davis, M. (1971). That's interesting!: Towards a phenomenology of sociology and a sociology of phenomenology. Philosophy of the Social Sciences, 1, 309-344.

Dijksterhuis, A., \& van Knippenberg, A. (1998). The relation between perception and behavior or how to win a game of trivial pursuit. Journal of Personality and Social Psychology, 71(2), 865-877.

Driver, M. J., \& Streufert, S. (1969) Integrative complexity: An approach to individuals and groups as information-processing systems. Administrative Science Quarterly, 14(2), 272-285.

Dolan, R. J. (2002). Emotion, cognition, and behavior. Science, New Series, 298(5596), 1191-1194.

Dunn, D. S., \& Wilson, T. D. (1991). When the stakes are high: A limit to the illusion of control effect. Social Cognition, 8, 305-328.

Einhorn, H. J., \& Hogarth, R. M. (1975). Unit weighting schemes for decision making. Organizational Behavior and Human Performance, 13, 171-192.

Elliot, A. J., \& Harackiewicz, J. M. (1996). Approach and avoidance achievement goals and intrinsic motivation: A mediational analysis. Journal of Personality and Social Psychology, 70(3), 461-475. 
Frensch, P. A. (1994). Composition during serial learning: A serial position effect. Journal of Experimental Psychology: Learning, Memory, and Cognition, 20(2), 423-443.

Gackowski, Z. J. (2006). Quality of informing: Bias and disinformation philosophical background and roots. Issues in Informing Science and Information Technology, 3, 731-744 Retrieved from http://informingscience.org/proceedings/InSITE2006/IISITZbig250.pdf

Gilbert, D. (2007). Stumbling on happiness. New York: Knopf.

Gigerenzer, G. (2004). Fast and frugal heuristics: The tools of bounded rationality. In D. J. Koehler\& N. Harvey (Eds.), Blackwell handbook of judgment and decision making. Malden, MA: Blackwell Publishing.

Gill, C. (2006). Confessions of a neophyte distance learner and full-time procrastinator. eLearn Magazine, $38(1)$, posted $7 / 28 / 2006$. Retrieved on $6 / 4 / 08$ from http://www.elearnmag.org/subpage.cfm?section=case_studies\&article=38-1

Gill, T. G. (1996). Expert systems: Task change and intrinsic motivation. MIS Quarterly, 20(3), 301-329.

Gill, T. G. (2008a). A psychologically plausible goal-based utility function. Informing Science: the International Journal of an Emerging Transdiscipline, 11, 227-252. Retrieved from http://inform.nu/Articles/Vol11/ISJv11p227-252Gill220.pdf

Gill, T.G. (2008b). Reflections on researching the rugged fitness landscape. Informing Science: the International Journal of an Emerging Transdiscipline, 11, 165-196. Retrieved from http://inform.nu/Articles/Vol11/ISJv11p165-196Gill219.pdf

Gill, T.G. (2008c). Structural complexity and effective informing. Informing Science: the International Journal of an Emerging Transdiscipline, 11, 253-279. Retrieved from http://inform.nu/Articles/Vol11/ISJv11p253-279Gill223.pdf

Gill, T. G., \& Bhatacherjee, A. (2007). The informing sciences at a crossroads: The role of the client. Informing Science: the International Journal of an Emerging Transdiscipline, 10, 17-39. Retrieved from http://inform.nu/Articles/Vol10/ISJv10p017-039Gill317.pdf

Gill, T. G., \& Hicks, R. (2006). Task complexity and informing science: A synthesis. Informing Science: the International Journal of an Emerging Transdiscipline, 9, 1-30. Retrieved from http://inform.nu/Articles/Vol9/v9p001-030Gill46.pdf

Gill, T. G., \& Saunders, C. S. (1997). Intrinsic motivation and IT adoption. Journal of Management Systems, 9, 1-4.

Gladwell, M. (2000). The tipping point. New York: Back Bay Books.

Gladwell, M. (2005). Blink. New York: Back Bay Books.

Guber, P. (2007). The four truths of the storyteller. Harvard Business Review, December, 52-59.

Hackman, J. R., \& Oldham, G. R. (1980). Work redesign. Reading, MA: Addison Wesley.

Heath, C., \& Heath, D. (2007). Made to stick. New York, NY: Random House.

Herring, H., Job-Sluder, K., Scheckler, R., \& Barab, S. (2002). Searching for safety online: Managing 'trolling' in a feminist forum. The Information Society, 18, 371-384.

Hirshleifer, J., \& Riley, J. G. (1992). The analytics of uncertainty and information. Cambridge, U.K.: Cambridge University Press.

Hoffrage, U. (2004). Overconfidence. In R. F. Pohl (Ed.), Cognitive illusions (pp. 235-254). Hove, U.K.: Psychology Press.

Jamieson, K., \& Hyland, P. (2006). Good intuition or fear and uncertainty: The effects of bias on information systems selection decisions. Informing Science: the International Journal of an Emerging Transdiscipline, 9, 49-69. Retrieved from http://inform.nu/Articles/Vol9/v9p049-069Jamieson60.pdf 
Ku, G., Malhotra, D., \& Murnighan, J. K. (2005). Towards a competitive arousal model of decisionmaking: A study of auction fever in live and Internet auctions. Organizational Behavior and Human Decision Processes, 96, 89-103.

Kuhn, T. S. (1970). The structure of scientific revolutions (2nd ed.). Chicago, IL: University of Chicago.

Langer, E. J. (1975). The illusion of control. Journal of Personality and Social Psychology, 32, 311-328.

Loewenstein, G. (1996). Out of control: Visceral influences on behavior. Organizational Behavior and Human Decision Processes, 65(3), 272-292.

Lord, K. R., \& Burnkrant, R. E. (1993). Attention versus distraction: The interactive effect of program involvement and attentional devices on commercial programming. Journal of Advertising, 22(1), 47-60.

Luce, M. F., Payne, J. W., \& Bettman, J. R. (1999). Emotional trade-off difficulty and choice. Journal of Marketing Research, 36(2), 143-159.

March, J. G., \& Shapira, Z. (1987). Managerial perspectives on risk and risk taking. Management Science, 33(11), 1404-1418.

Miller, G. A. (1967). The psychology of communication. New York, NY: Basic Books.

Morris, J. A., \& Feldman, D. C. (1996). The dimensions, antecedents, and consequences of emotional labor. Academy of Management Review, 21(4), 986-1010.

Morison, E. (1966). Man, machines and modern times. Cambridge, MA: MIT Press.

Mussweiler, T., Englich, B., \& Strack, F. (2004). Anchoring effect. In R. F. Pohl (Ed.), Cognitive illusions (pp. 183-200). Hove, UK: Psychology Press.

Neves, D. M., \& Anderson, J. R. (1981). Knowledge compilation: Mechanisms for the automization of cognitive skills. In J. R. Anderson (Ed.), Cognitive skills and their acquisition (pp. 57-84). Hillsdale, NJ: Lawrence Earlbaum.

Newell, A. (1990). Unified theories of cognition. Cambridge, MA: Harvard University Press.

Nissen, H-E. (2007). Using double helix relationships to understand and change informing systems. Informing Science: the International Journal of an Emerging Transdiscipline, 10, 21-62. Retrieved from http://inform.nu/Articles/Vol10/DblHelix021-062.pdf

Oswald, M. E., \& Grosjean, S. (2004). Confirmation bias. In R. F. Pohl (Ed.), Cognitive illusions (pp. 7996). Hove, U.K.: Psychology Press.

Pang, N., \& Shauder, D. (2007). The culture of information systems in knowledge-creating contexts: The Role of user-centred design. Informing Science: the International Journal of an Emerging Transdiscipline, 10, 203-235. Retrieved from http://inform.nu/Articles/Vol10/DblHelix203-235.pdf

Payne, J., Bettman, J., \& Johnson, E. (1993). The adaptive decision maker. Cambridge, UK: Cambridge University Press.

Politser, P. (2008). Neuroeconomcs. Oxford, UK: Oxford University Press.

Reber, R. (2004). Availability. In R. F. Pohl (Ed.), Cognitive illusions (pp. 147-164). Hove, U.K.: Psychology Press.

Rogers, E. M. (2003). Diffusion of innovations (5th ed.). New York: Free Press.

Rottenstreich, Y., \& Shu, S. (2004). The connections between affect and decision making: Nine resulting phenomena. In D. J. Koehler \& N. Harvey (Eds.), Blackwell handbook of judgment and decision making (pp. 444-463). Malden, MA: Blackwell.

Rumelhart, D. E., \& Norman, D. A. (1981). Analogical processes in learning. In J. R. Anderson (Ed.), Cognitive skills and their acquisition (pp. 335-359). Hillsdale, NJ: Lawrence Earlbaum.

Russo, J. E., \& Dosher, B. A. (1983). Strategies for multiattribute binary choice. Journal of Experimental Psychology: Learning, Memory and Cognition, 9, 676-696. 
Russo, J. E., Meloy, M. G., \& Medvec, V. H. (1998). Predecisional distortion of product information. Journal of Marketing Research, 35(4), 438-451.

Rynes, S., Giluk, T., \& Brown, K. (2007). The very separate worlds of academic and practitioner periodicals in human resource management: Implications for evidence-based management. Academy of Management Journal, 50(5), 987-1008.

Sierra, J. J., \& Hyman, M. R. (2006). A dual-process model of cheating intentions. Journal of Marketing Education, 28(3), 193-204.

Simon, H. A. (1955). A behavioral model of rational choice. Quarterly Journal of Economics, 69, 129-138.

Simon, H. A. (1992). Altruism and economics. Eastern Economic Journal, 18(1), 73-83.

Simon, H. A., \& Hayes, J. R. (1976). The understanding process: Problem isomorphs. In H. A. Simon, (1979). Models of thought (pp. 477-512). New Haven, CT: Yale University Press.

Soman, D. (2004). Framing, loss aversion, and mental accounting. In D. J. Koehler \& N. Harvey (Eds.), Blackwell handbook of judgment and decision making (pp. 379-398). Malden, MA: Blackwell.

Soman, D., \& Cheema, A. (2002). The effect of credit on spending decisions: The role of the credit limit and credibility. Marketing Science, 21(1), 32-53.

Streufert, S., \& Streufert, S. (1978). Behavior in the complex environment. New York, NY: Wiley.

Teigen, K. H. (2004). Judgment by Representativeness. In R. F. Pohl (Ed.), Cognitive illusions (pp. 165182). Hove, U.K.: Psychology Press.

Thompson, S. C. (2004). Illisions of control. In R. F. Pohl (Ed.), Cognitive illusions (pp. 115-126). Hove, U.K.: Psychology Press.

Tversky, A. (1969). Intransitivity of preferences. Psychological Review, 76, 31-48.

Tversky, A. (1972). Elimination by aspects: A theory of choice. Psychological Review, 79, 281-299.

Tversky, A., \& Kahneman, D. (1982a). Availability: A heuristic for judging frequency and probability. In D. Kahneman, P. Slovic, \& A. Tversky (Eds.), Judgement under uncertainty: Heuristics and biases (pp. 163-178). Cambridge, UK: Cambridge University Press.

Tversky, A., \& Kahneman, D. (1982b). Judgments of and by representativeness. In D. Kahneman, P. Slovic, \& A. Tversky (Eds.), Judgement under uncertainty: Heuristics and biases (pp. 84-98). Cambridge, UK: Cambridge University Press.

Tversky, A., \& Kahneman, D. (1988). Rational choice and the framing of decisions. In D. E. Bell, A. Raiffa, \& A. Tversky (Eds.), Decision making: Descriptive, normative and prescriptive interactions (pp. 167-192). Cambridge, UK: Cambridge University Press.

Ulene, V. (2007). Car Keys? Not so fast. Los Angeles Times. Jan 8.

Usher, M., \& McClelland, J. L. (2004). Loss aversion and inhibition in dynamical models of multialternative choice. Psychological Review, 111(3), 757-769.

Whittaker, R. (2007). Applying phenomenology and hermeneutics in IS design: A report on field experiences. Informing Science: the International Journal of an Emerging Transdiscipline, 10, 63-96. Retrieved from http://inform.nu/Articles/Vol10/DblHelix063-096.pdf 


\section{Biography}

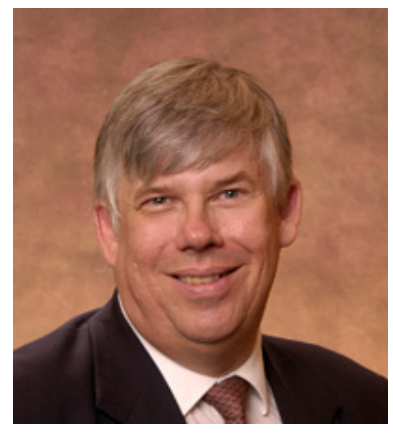

Grandon Gill is an Associate Professor in the Information Systems and Decision Sciences department at the University of South Florida. He holds a doctorate in Management Information Systems from Harvard Business School, where he also received his M.B.A. His principal research areas are the impacts of complexity on decisionmaking and IS education, and he has published many articles describing how technologies and innovative pedagogies can be combined to increase the effectiveness of teaching across a broad range of IS topics. Currently, he is an Editor of the Journal of IT Education and an Associate Editor for the Decision Science Journal of Innovative Education. 